\title{
A rare case of invasive mole with silent uterine perforation
}

\author{
Sahaja Kittur*, Venktesh, Ramlingappa A.
}

Department of Obstetrics \& Gynecology, Karnataka Institute of Medical Sciences, Hubli-580022, Karnataka, India

Received: 13 January 2013

Accepted: 20 January 2013

*Correspondence:

Dr. Sahaja Kittur

E-mail: drsahajakittur@rediffmail.com

\begin{abstract}
Invasive mole is a condition where a molar pregnancy, such as a partial hydatidiform mole or complete hydatidiform mole, invades the wall of the uterus, potentially spreading and metastasizing to other parts of the body. Here is a case which presented with history of evacuation for molar pregnancy. She presented with irregular p/v bleeding on and off and after admission silent perforation with massive haemoperitoneum was detected for which emergency laparotomy with hysterectomy was done (operative photographs enclosed). She was given massive transfusion. She recovered and followed up till her beta hCG levels were within normal limits. As patient presented to us with haemoperitoneum and intraoperative there was invasion into whole of the uterus, it could not be saved and hysterectomy was done. Patient received 6 cycles of EMACO regime chemotherapy and was followed up for 6 months after beta hCG levels were within normal limits.
\end{abstract}

Keywords: Invasive mole, Molar pregnancy, Antepartum haemorrhage

\section{INTRODUCTION}

Invasive mole is a condition where a molar pregnancy, such as a partial hydatidiform mole or complete hydatidiform mole, invades the wall of the uterus, potentially spreading and metastasizing to other parts of the body (such as the vagina or lungs). ${ }^{1-3}$

Invasive moles occur in about $20 \%$ of molar pregnancies but are more common in complete molar pregnancies than in partial molar pregnancies. ${ }^{3,4}$ Invasive moles can develop both before and after treatment by D \& C. ${ }^{5}$ Treatment of an invasive mole may include chemotherapy.

\section{CASE REPORT}

A 21 years old lady was admitted on 20/07/2012 at KIMS, Hubli with the complaints of irregular $\mathrm{p} / \mathrm{v}$ bleeding following evacuation. Patient gives history of being diagnosed to have a molar pregnancy in a private hospital on 19/05/2012, about 15 days after which she underwent suction and evacuation. Patient did not have any $\mathrm{p} / \mathrm{v}$ bleeding till 4 days back.
Patient did not give any history of passage of grape like vesicles $\mathrm{p} / \mathrm{v}$. Patient was a primigravida with a nonconsanguineous marriage of 4 years. General physical examination showed severe pallor and bilateral pitting pedal oedema. Per abdomen examination showed a 20 week size uterus, soft and non-tender. Per vaginal examination showed 20 week uterus, there was no p/v bleeding or any vaginal nodules. Patient was investigated at KIMS, Hubli. Complete hemogram showed a dimorphic anemia with relative neutrophilia with $\mathrm{Hb}$ $3.7 \mathrm{gm} \%$, blood group being ' $\mathrm{A}$ ' positive. Beta hCG was $7,66,705.34 \mathrm{mIU} / \mathrm{mL}$, thyroid profile was normal. USG abdomen with doppler done at KIMS showed a gross haemoperitoneum and bilateral theca lutein cysts. Uterine contour and myometrial echotexture could not be made out. An emergency laparotomy was performed under general anesthesia which lasted for 2 hours. There was massive haemoperitoneum of 3.5-4 litres with grape-like vesicles floating in the peritoneum. Bunch of vesicles found in the paracolic gutter (Figure 1). Rent on the posterior uterine wall $3 \times 2 \mathrm{~cm}$ through which vesicles were coming out (Figure 2). 


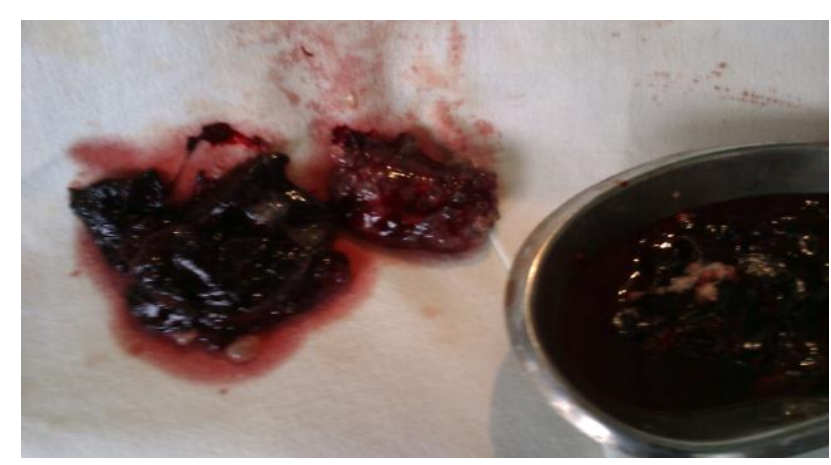

Figure 1: Vesicles collected from the abdominal cavity.

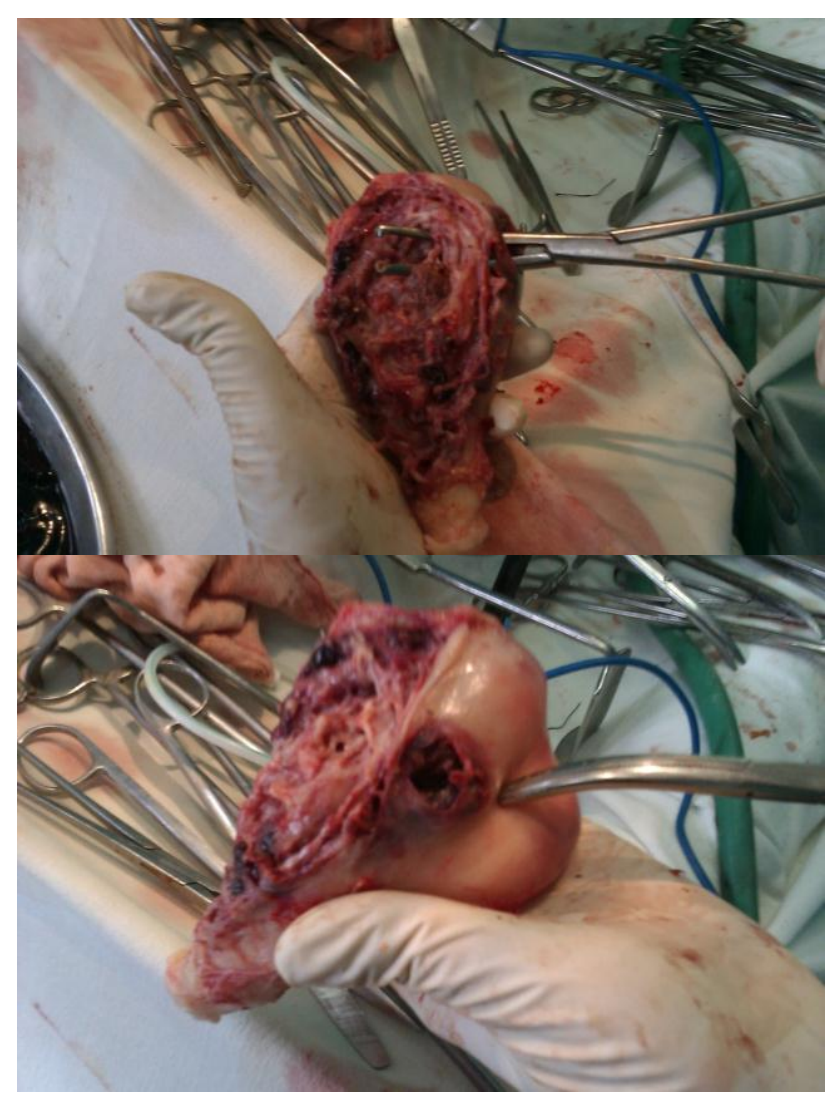

Figure 2: Vesicles coming out through the uterine wall.

One more rent on left lateral wall of the uterus $2 \times 4 \mathrm{~cm}$ which opened to the peritoneum (Figure 2) through the posterior leaf of the broad ligament, through which there was continuous bleed. Hysterectomy was performed as the edges of the rents were jagged and lacerated and the posterior wall of the uterus was very thin. Bilateral internal iliac ligation was done to control the hemorrhage. Despite the above measures there was bleeding from 2 sites: 1. Left infundibulopelvic ligament and 2. At the level of the left Mackenrodt's ligament.
Multiple bites were carefully taken at both these sites to secure hemostasis. Abdominal drain was placed in the pelvic cavity. Specimen was sent for HPR. Patient was given ICU care in the post-operative period. She received more than 20 blood and blood products to correct her anemia and DIC post-operatively along with higher antibiotics. It took nearly 4-5 days till patient was shifted towards and later recovered. Histopathology confirmed the diagnosis of an invasive mole. As patient presented to us with haemoperitoneum and intraoperative there was invasion into whole of the uterus, it could not be saved and hysterectomy was done. Patient received 6 cycles of EMACO regime chemotherapy and was followed up for 6 months after beta hCG levels were within normal limits. Though patient was from very low socioeconomic status she was educated and counselled for surrogate pregnancy.

\section{DISCUSSION}

An invasive mole causing uterine perforation is a rare occurence. ${ }^{3}$ Although an invasive mole is generally less malignant than choriocarcinoma, it may be associated with fatal metastases. The use of chemotherapeutic agents in invasive mole is controversial. Although the beta-hCG in this case showed a downward trend, there was some doubt as to whether all the molar tissue had been cleared. On balance, we felt the patient would benefit from chemotherapy.

\section{Funding: No funding sources}

Competing interests: There are no competing interests to declare

Ethical approval: Not required

\section{REFERENCES}

1. Xiang Y, Yang X, Du J. The role of hysterectomy in the therapy of gestational trophoblastic tumor. Zhonghua Zhong Liu Za Zhi 1999;21:139-41.

2. Xiang Y, Yang X, Zhang L, Song H. Evaluation of emergency surgery in gestational trophoblastic tumours. Zhongguo Yi Xue Ke Xue Yuan Xue Bao 1997;19:369-72.

3. Atala C, Riedemann R, Biotti M, Ramírez F, Paublo M. Invasive mole with uterine rupture. Rev Chil Obstet Ginecol 1992;57:356-8.

4. Chandran R, Tham KY, Rose I. Perforating invasive mole masquerading as an ovarian tumour--case report. Med J Malaysia 1991;46:255-8.

5. Garza de la Garza R, Livas Rodríguez S, Ploneda González C. Chorioadenoma destruens: presentation of 2 cases. Ginecol Obstet Mex 1989;57:139-41.

DOI: $10.5455 / 2320-1770$. ijrcog20130222

Cite this article as: Kittur S, Venktesh, Ramlingappa A. A rare case of invasive mole with silent uterine perforation. Int J Reprod Contracept Obstet Gynecol 2013;2:109-10. 